\title{
EFFECT OF SURFACE STEPS ON THE MICROSTRUCTURE OF LATERAL COMPOSITION MODULATION
}

\author{
D. M. Follstaedt ${ }^{1}$, A. G. Norman ${ }^{2}$, J. L. Reno ${ }^{1}$, E. D. Jones ${ }^{1}$, R. D. Twesten ${ }^{3}$, S. R. Lee ${ }^{1}$, \\ H. Moutinho, and A. Mascarenhas ${ }^{2}$
}

${ }^{1}$ Sandia National Laboratories, M.S. 1056, Albuquerque, NM 87185-1056

${ }^{2}$ National Renewable Energy Laboratory, 1617 Cole Blvd., Golden, CO 80401-3393

${ }^{3}$ University of Illinois, Urbana, IL 61801-2985

\begin{abstract}
Growth of InAs/AlAs short-period superlattices on appropriately miscut (001) InP substrates is shown to alter the microstructure of composition modulation from a 2D organization of short compositionally enriched wires to a single dominant modulation direction and wire lengths up to $\sim 1 \mu \mathrm{m}$. The effects of miscut are interpreted in terms of surface step orientation and character. The material is strongly modulated and exhibits intense optical emission. The 1D modulations appear potentially useful for new devices that take advantage of the preferred direction formed in the growth plane.
\end{abstract}

Composition modulation is being actively investigated as a method to develop laterally patterned microstructures in two-component semiconductors. These systems (e.g., InP-GaP [1,2], InAs-GaAs [3,4], and InAs-AlAs [5,6]) can self-assemble into narrow regions ("wires") alternatingly enriched in the two components. The compositional variations induce significant changes in bandstructure relative to alloys of uniform composition [7-10], and the $\sim 10 \mathrm{~nm}$ widths are expected to produce quantum confinement of carriers. Deposition of the two components as vertical short-period superlattices has been shown to result in intense lateral modulations, are as much as 10's mole \% in InAs/AlAs [11]. The InP/GaP [1,2] and InAs/GaAs [3] structures grown on (001) substrates are reported to assemble into a uniform structure of wires extending in the [1-10] direction with modulation along [110]. Such a microstructure appears favorable for polarized optical emitters and detectors and for lateral solar cells because it introduces a preferred direction for polarization and conductivity. Composition modulation in InAs/GaAs is being investigated to produce quantum-wire lasers with improved thermal stability $[8,9]$.

Superlattices of InAs/AlAs on (001) InP show notably different microstructures: two modulation directions are seen, and depend upon the average composition, $\operatorname{In}_{\mathrm{x}} \mathrm{Al}_{1-\mathrm{x}} \mathrm{As}$ [6]. Superlattices slightly AlAs-rich with respect to the lattice-matched condition $(x=0.52)$ are in tension and exhibit modulations along [310] and [130], while InAs-rich superlattices are in compression and exhibit modulations nearly along [100] and [010]. In both cases, the two modulations interfere, limiting wire lengths to $<\sim 0.2 \mu \mathrm{m}$ and often $\sim 30 \mathrm{~nm}$; thus uniform 1D modulation is not achieved. Here we use transmission electron microscopy (TEM) to show that uniform, 1D-modulated microstructures can be achieved with InAs/AlAs superlattices grown on miscut InP substrates. The results indicate that surface steps play an important role in producing lateral modulation during growth. The insights gained here are also important for InAs/GaAs and InP/GaP since we achieve longer wire lengths, up to $\sim 1 \mu \mathrm{m}$; moreover, detailed examination indicates that these systems also exhibit some 2D-modulation character $[2,12,13]$. 


\section{DISCLAIMER}

This report was prepared as an account of work sponsored by an agency of the United States Government. Neither the United States Government nor any agency thereof, nor any of their employees, make any warranty, express or implied, or assumes any legal liability or responsibility for the accuracy, completeness, or usefulness of any information, apparatus, product, or process disclosed, or represents that its use would not infringe privately owned rights. Reference herein to any specific commercial product, process, or service by trade name, trademark, manufacturer, or otherwise does not necessarily constitute or imply its endorsement, recommendation, or favoring by the United States Government or any agency thereof. The views and opinions of authors expressed herein do not necessarily state or reflect those of the United States Government or any agency thereof. 


\section{DISCLAIMER}

\section{Portions of this document may be illegible}

in electronic image products. Images are produced from the best available original document. 
Our prior work shows that strong modulation is achieved in MBE-grown $(\operatorname{InAs})_{\mathrm{n}} /(\mathrm{AlAs})_{\mathrm{m}}$. superlattices with $\mathrm{n}, \mathrm{m} \approx 2$ and $\mathrm{x} \approx 0.52[14,15]$. Here, $(001) \mathrm{InP}$ substrates with no miscut and miscuts $2^{\circ}$ toward (101), (-101), (111)A and (1-11)B were used. For superlattices in tension we deposited $n=m=1.95$; $x$-ray diffraction analyses [14] gave an average of $x=0.50$ with variations of \pm 0.01 for this series. For specimens in compression, $\mathrm{n}=1.99, \mathrm{~m}=1.43$ were deposited, with $\mathrm{x}=0.57$ and variations of \pm 0.02 being found. We have found that growth at $545^{\circ} \mathrm{C}$ is optimum for strong modulation. Growth on the compressive specimens was initiated at $540^{\circ} \mathrm{C}$ but the temperature was expected to rise to $\approx 545^{\circ} \mathrm{C}$ due to additional heating from the effusion cells. The tensile specimens were grown with the wafer temperature actively controlled at this value by monitoring the optical absorption threshold of the substrate.

Plan-view TEM was used to assess the effects of substrate miscut on microstructure. Specimens were back-thinned by mechanical polishing with diamond paste and then ion milling at $2^{\circ}$ glancing incidence to produce thin area for examination. Figure 1 shows images obtained with the compositionally-sensitive (200) dark-field imaging method [11] from specimens in tension. The specimen in Fig. 1a was grown on (001) (no miscut) and exhibits two modulation directions; regions enriched in InAs appear bright. Many regions only 30 nm long result from interference between the two modulations. Cross-section TEM has shown that enriched regions grow as vertical columns $[5,11]$. In areas with one locally dominant modulation, short wires are observed, $\lesssim 0.2 \mu \mathrm{m}$. The Fourier transform of the dark-field image (at right) shows two sets of diffuse spots on either side of the [110] direction with their centers separated by $53^{\circ}$, in agreement with the [310] and [130] directions identified earlier [6]. The modulations were also detected by AFM as ridges on the specimen surface, allowing directions to be determined with respect to flats on the InP wafer.

Figure $1 \mathrm{~b}$ is the corresponding image for a substrate miscut toward (101). The [310] modulation direction dominates as seen in the image and Fourier transform. Wire lengths up to $\sim 0.4 \mu \mathrm{m}$ are found, although areas with [130] modulation and short lengths remain. The image exhibits a black line between the bright In-rich wires and parallel dark-gray, Al-rich wires; this is due to a null in the (002) scattering factor and indicates that the modulation amplitude is quite large [11]. We have also used characteristic $\mathrm{x}$-rays generated in a scanning transmission electron microscope with a sub-nanometer electron beam size to measure local compositions in this specimen. Compositions of $\operatorname{In}_{0.70} \mathrm{Al}_{0.30} \mathrm{As}$ and $\mathrm{In}_{0.43} \mathrm{Al}_{0.57} \mathrm{As}$ were determined, demonstrating that the modulation amplitude remains large with miscut substrates.

The result in Fig. $1 \mathrm{~b}$ can be interpreted in terms of the direction of the steps produced on the growth surface by the miscut, as shown in Fig. 1c. The two modulation directions and their wires are also shown. The miscut to (101) induces steps that on average extend along the [010] or y direction; these are misoriented by only $18^{\circ}$ from. the wires of the [310] modulation, but by $72^{\circ}$ from those of [130]. The wires closest to parallel to the steps were enhanced by the miscut, or equivalently, the modulation nearly along the step-flow direction was enhanced. Miscutting toward (-101) produced the same microstructure; step-flow in the opposite direction appears . equally effective. We also examined miscut toward (111)A, for which A-type steps extend along [1-10] at $26.5^{\circ}$ from. each of the original wire directions, favoring neither. In this case (not shown), two modulation directions were retained, but the angle between them narrowed to $43^{\circ}$. Miscutting toward (1-11)B produced steps along [110] at $63^{\circ}$ from the original wire directions and resulted in no change in the microstructure.

The effects of substrate miscut in the series grown in compression are similar but more dramatic. Growth on (001) substrates produces modulations nearly along [100] and [010], and short "dot-like" enriched regions; see fig. 3 in Ref. [6]. The two directions lie slightly inside 
these axes and toward the [110] direction, $86^{\circ}$ apart from each other. When the specimen is miscut toward (101), the [100] modulation becomes dominant, as seen in Fig. 2a and its Fourier transform. The steps are again parallel to the wires for this modulation. The wires extend up to $\sim 1 \mu \mathrm{m}$, longer than reported for $\operatorname{InP} / \mathrm{GaP}(0.3 \mu \mathrm{m})[2,13]$ or InAs/GaAs $(0.3-0.5 \mu \mathrm{m})$ [8]. Miscutting toward (111)A also produces $\sim 1 \mu \mathrm{m}$ wire lengths as seen in Fig. $2 \mathrm{~b}$, but the modulation direction is then [110]. For compressive growth, the two original modulations essentially collapsed into one modulation along [110] with this miscut. Some dot-like regions remain interspersed between the long wires, and the width of the spot in the Fourier transform indicates that a range of orientations is present. Finally, growth on a substrate miscut toward (1-11)B again retains the two original modulations, but the wires are somewhat more elongated and the two directions appear better defined. We can assess the period of the modulations with TEM and with satellites detected by $\mathrm{x}$-ray diffraction [14]. It is notable that for both tension and compression, including all the orientations examined, the modulation wavelength remains remarkably constant, between $20-30 \mathrm{~nm}$.

Let us consider factors that govern the directions of composition modulation. The $<100>$ directions are favored because they are the elastically soft directions on the (001) surface of cubic materials. On the other hand, modulations are predominantly along the [110] direction in InAs/GaAs and InP/GaP. In compressive InAs/AlAs the two modulations are offset slightly $\left(2^{\circ}\right)$ from the $\langle 100\rangle$ toward [110], while in tensile specimens the offset is larger, $18^{\circ}$ for the two $<310>$ modulations (see Fig. 1c). These observations suggest a competition between [100] and [110] for modulations in InAs/AlAs, with compromise directions being adopted. The redirection of modulation toward [110] with miscut toward (111)A, which is very pronounced in compression, suggests that A-type step edges along [1-10] are responsible for the [110] preference. Retaining two directions with miscut toward (1-11)B, instead of redirecting the original modulations toward [1-10] (in analogy to (111)A miscut), is consistent with modulation directions in the $\mathrm{x}>0, \mathrm{y}<0$ quadrant of the (001) plane not being reported. For miscuts toward (101), the average step edges are along [010]; they are expected to consist of equal lengths both A-type step edges along [1-10] and B-type step edges along [110], as in GaAs [16,17]. In this combination, the effects of A-type steps do not change the direction to [110], but original modulation directions within $18^{\circ}$ of the average step-flow direction are amplified.

A recent theoretical treatment [18] of compositional instability during growth of random alloys includes anisotropies due to step directions, diffusion and cubic symmetry. It predicts modulation directions for modulation that vary with these properties, but steps are predicted to induce modulation along the step edges, instead of perpendicular to them as for (111)A miscuts. Since the modulations in our superlattices are much more intense than any that might be present in our alloy buffer layers, we think that a proper treatment of this instability needs to include deposition as individual component layers.

Our modulated layers exhibit intense photoluminescence at energies consistent with the modulation amplitude [10]. The tensile specimen with miscut toward (101) has an optical emission peak at $1.07 \mathrm{eV}$, as compared to $1.58 \mathrm{eV}$ predicted for an alloy with $\mathrm{x}=0.50$. For this strongly modulated specimen, emission is expected at an energy characteristic of the local In-rich composition of $\operatorname{In}_{0.70} \mathrm{Al}_{0.30} \mathrm{As}$, or $1.09 \mathrm{eV}$, which agrees well with that observed. The favorable electron-optical properties demonstrated by this result indicate that these materials are suitable for devices. Thus, to summarize, growth of InAs/AlAs superlattices on appropriately miscut (001) InP substrates produces very uniform 1D composition modulation, with microstructures of long $(\sim 1 \mu \mathrm{m})$, thin $(\sim 10 \mathrm{~nm})$ wires as needed for potential new devices. 
This work is supported by Division of Materials Sciences, Office of Basic Energy Sciences of the U. S. Department of Energy. Sandia is a multiprogram laboratory operated by Sandia Corp., a Lockheed Martin Company, for the U. S. Department of Energy under contract DEAC04-94A185000. NREL is a national laboratory of the U. S. Department of Energy operated by the Midwest Research Institute, Battelle, and Bechtel. Work at the University of Illinois was done in the Center for Microanalysis of Materials under U. S. Department of Energy grant DEFG02-91ER45439.

\section{References}

1. K. C. Hsieh, J. N. Baillargeon and K. Y. Cheng, Appl. Phys. Lett. 57, 2244 (1990).

2. A. C. Chen, A. M. Moy, L. J. Chou, K. C. Hsieh and K. Y. Cheng, Appl. Phys. Lett. 66, 2694 (1995). Average wire lengths of $0.3 \mu \mathrm{m}$ are shown.

3. K. Y. Cheng, K. C. Hsieh and J. N. Baillargeon, Appl. Phys. Lett. 60, 2892 (1992).

4. T. Okada, G. C. Weatherly and D. W. McComb, J. Appl. Phys. $\underline{81}, 2185$ (1997).

5. J. Mirecki Millunchick, R. D. Twesten, S. R. Lee, D. M. Follstaedt, E. D. Jones, S. P. Ahrenkiel, Y. Zhang, H. M. Cheong and A. Mascarenhas, MRS Bulletin 22 (7), 38 (1997).

6. A. G. Norman, S. P. Ahrenkiel, H. Moutinho, M. M. Al-Jassim, A. Mascarenhas, J. Mirecki Millunchick, S. R. Lee, R. D. Twesten, D. M. Follstaedt, J. L. Reno and E. D. Jones, Appl. Phys. Lett. $\underline{73}, 1844$ (1998).

7. A. Mascarenhas, R. G. Alonso, G. S. Horner, S. Froyen, K. C. Hsieh and K. Y. Cheng, Superlattices and Microstructures $\underline{12}, 57$ (1992).

8. S. T. Chou, K. Y. Cheng, L. J. Chou and K. C. Hsieh, Appl. Phys. Lett. 66, 2220(1005).

9. D. E. Wohlert, A. M. Moy, L. J. Chou, K. Y. Cheng and K. C. Hsieh, J. Vac. Sci. Technol. B 16,1352 (1998).

10. E. D. Jones; D. M. Follstaedt, S. R. Lee, J. L. Reno, J. Mirecki Millunchick, S. P. Ahrenkiel, A. Mascarenhas, A. G. Norman, Y. Zhang and R. D. Twesten, Thin Solid Films 357, 31 (1999).

11. R. D. Twesten, D. M. Follstaedt, S. R. Lee, E. D. Jones, J. L. Reno, J. Mirecki Millunchick, A. G. Norman, S. P. Ahrenkiel and A. Mascarenhas, Phys. Rev. B 60, 13619 (1999).

12. A. G. Norman, unpublished TEM images of InP/GaP exhibit some 2D character. Plan-view images in Ref. [2] (fig. 3, InAs/GaAs) and Ref. 13 (fig. 4c, InP/GaP) also exhibit some degree of 2D modulation, with wire orientations varying slightly to either side of [1-10].

13. K. C. Hsieh and K. Y. Cheng, Mat. Res. Soc. Symp. Proc. 379 , 145 (1995).

14. S. R. Lee, J. Mirecki Millunchick, R. D. Twesten, D. M. Follstaedt, J. L. Reno, S. P. Ahrenkiel and A. G. Norman, J. Materials Science: Materials In Electronics 10, 191 (1999).

15. S. P. Ahrenkiel, A. G. Norman, M. M. Al-Jassim, A. Mascarenhas, J. Mirecki Millunchick, R. D. Twesten, S. R. Lee, D. M. Follstaedt and E. D. Jones, J. Appl. Phys. $\underline{84}, 6088$ (1998).

16. S. Ohkouchi and I. Tanaka, Japn. J. Appl. Phys. 스, L1826 (1991). 
17. V. P. Evtikhiev, V. E. Tokranov, A. K. Kryzhanovskii, A. M. Boiko, R. A. Suris and A. N. Titkov, Semiconductors $\underline{32}, 765$ (1998).

18. I. P. Ipatova, V.G. Malyshkin, A. A. Maradudin, V. A. Shchukin and R. F. Wallis, Phys. Rev. B $\underline{57}, 19968$ (1998).

\section{Figure Captions}

Figure 1. a,b) TEM images showing lateral composition modulation in InAs/AlAs superlattices with global tension grown on a) (001) InP, and b) (001) miscut $2^{\circ}$ toward (101). c) Schematic showing how the enhanced [310] modulation has wires lying more nearly parallel to the steps than [130].

Figure 2. TEM images showing lateral composition modulation in InAs/AlAs superlattices with global compression grown on (001) InP miscut $2^{\circ}$ toward a) (101), and b) (111)A. 

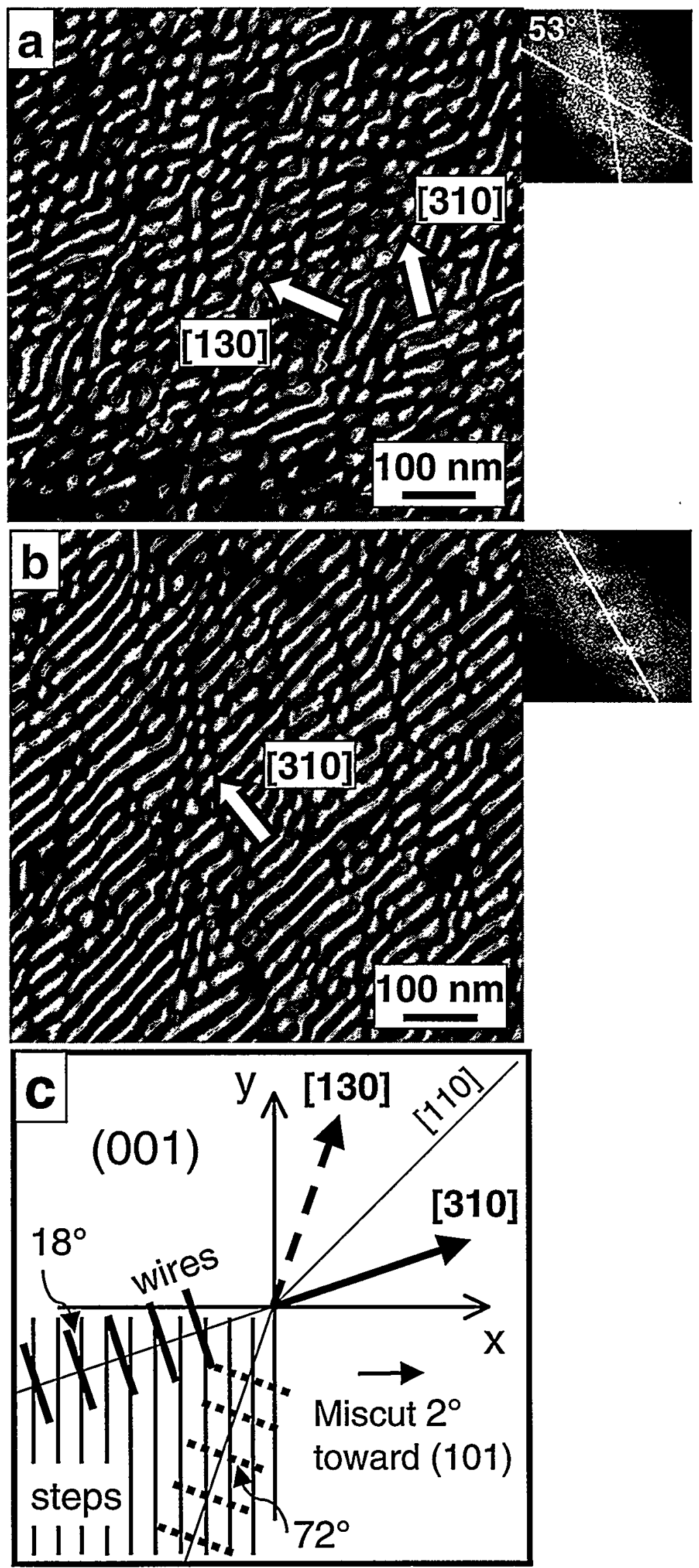

Follstaedt

Fig. 1 

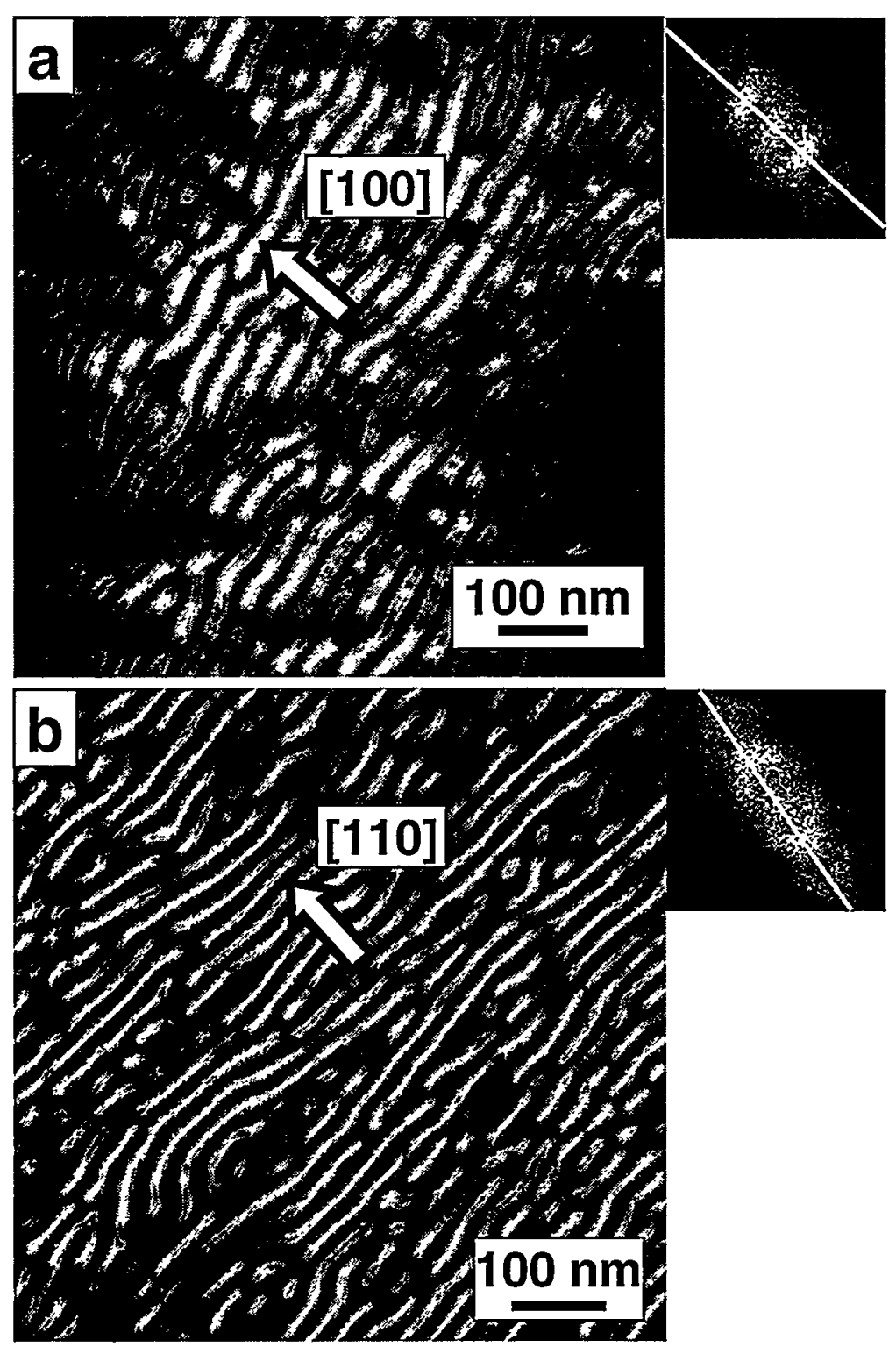

Follstaedt

Fig. 2 